\title{
Learning to Integrate versus Inhibiting Information Is Modulated by Age
}

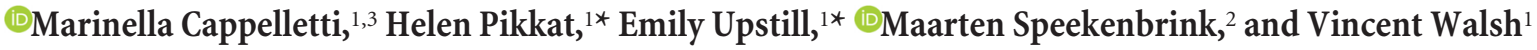 \\ ${ }^{1}$ Institute of Cognitive Neuroscience and ${ }^{2}$ Department of Experimental Psychology, University College London, London, WC1N 3AR, United Kingdom, and \\ ${ }^{3}$ Department of Psychology, Goldsmiths College, University of London, London, SE14 6NW, United Kingdom
}

Cognitive training aiming at improving learning is often successful, but what exactly underlies the observed improvements and how these differ across the age spectrum are currently unknown. Here we asked whether learning in young and older people may reflect enhanced ability to integrate information required to perform a cognitive task or whether it may instead reflect the ability to inhibit task-irrelevant information for successful task performance. We trained 30 young and 30 aging human participants on a numerosity discrimination task known to engage the parietal cortex and in which cue-integration and inhibitory abilities can be distinguished. We coupled training with parietal, motor, or sham transcranial random noise stimulation, known for modulating neural activity. Numerosity discrimination improved after training and was maintained long term, especially in the training + parietal stimulation group, regardless of age. Despite the quantitatively similar improvement in the two age groups, the content of learning differed remarkably: aging participants improved more in inhibitory abilities, whereas younger subjects improved in cue-integration abilities. Moreover, differences in the content of learning were reflected in different transfer effects to untrained but related abilities: in the younger group, improvements in cue integration paralleled improvements in continuous quantity (time and space), whereas in the elderly group, improvements in numerosity-based inhibitory abilities generalized to other measures of inhibition and corresponded to a decline in space discrimination, possibly because conflicting learning resources are used in numerosity and continuous quantity processing. These results indicate that training can enhance different, age-dependent cognitive processes and highlight the importance of identifying the exact processes underlying learning for effective training programs.

Key words: ageing; brain stimulation; learning strategies; neuroenhancement; parietal lobe; quantity processing

\section{Introduction}

Training programs aimed at improving learning of a cognitive ability have often proven successful in aging participants (Ball et al., 2002; Buitenweg et al., 2012; Anguera et al., 2013; Zimerman et al., 2013), but what exactly underlies the observed improvements and how these differ across the age spectrum are currently unknown. For instance, learning may reflect an enhancement in the ability to integrate information, for example, coming from different visual cues, or instead it may indicate improved ability to suppress task-irrelevant information. The distinction between cue-integration and inhibitory abilities is well known in classical studies of perception (Gottwald and Garner, 1972; Pomerantz

Received March 14, 2014; revised 0ct. 19, 2014; accepted Nov. 6, 2014.

Author contributions: M.C. designed research; M.C., H.P., and E.U. performed research; V.W. contributed unpublished reagents/analytic tools; M.C., H.P., E.U., and M.S. analyzed data; M.C., H.P., E.U., M.S., and V.W. wrote the paper.

This work was supported by a Royal Society Dorothy Hodgkin Fellowship, a Royal Society grant, and a British Academy grant. We thank Vincenzo Romei for advice and use of the Navon task, Daniele Didino and two anonymous reviewers for their comments on a previous version of this manuscript.

The authors declare no competing financial interests.

*H.P. and E.U. contributed equally to this work.

Correspondence should be addressed to Marinella Cappelletti, Institute of Cognitive Neuroscience, University College London, 17 Queen Square, London, WC1N 3AR, UK. E-mail: m.cappelletti@ucl.ac.uk or m.cappelletti@gold.ac.uk.

DOI:10.1523/JNEUROSCI.1018-14.2015

Copyright $\odot 2015$ the authors $\quad 0270-6474 / 15 / 352213-13 \$ 15.00 / 0$ and Pristach, 1989), showing that these abilities are distinct in development (Siegel, 1968; Shepp and Barrett, 1991) and aging (Roudaia et al., 2011).

Understanding the exact cognitive processes underlying learning is important because it may help to optimize training protocols and shape them according to specific learners (e.g., depending on their age) or training purposes. However, most of the previous training programs do not distinguish between different learning processes, and moreover training-related changes may not be substantial enough to allow detailed analyses of the underlying processes (Lee et al., 2012). One way to assist the cortical changes that support learning of a particular cognitive ability is by means of brain stimulation, such as transcranial random noise stimulation (tRNS), known to facilitate brain plasticity (Terney et al., 2008; Fertonani et al., 2011).

Here we combined cognitive training and tRNS in young and aging participants to measure whether learning (1) reflects enhanced cue integration or inhibition, (2) may be age dependent, or (3) is modulated by the type of cognitive training received (i.e., training only or combined with brain stimulation to parietal vs motor regions) and whether (4) cue integration or inhibition may differently affect other untrained but related continuous quantity abilities, such as time and space processing (Walsh, 2003), or inhibitory abilities in general. We trained participants on an established, parietal lobe-based measure of "number acu- 
A
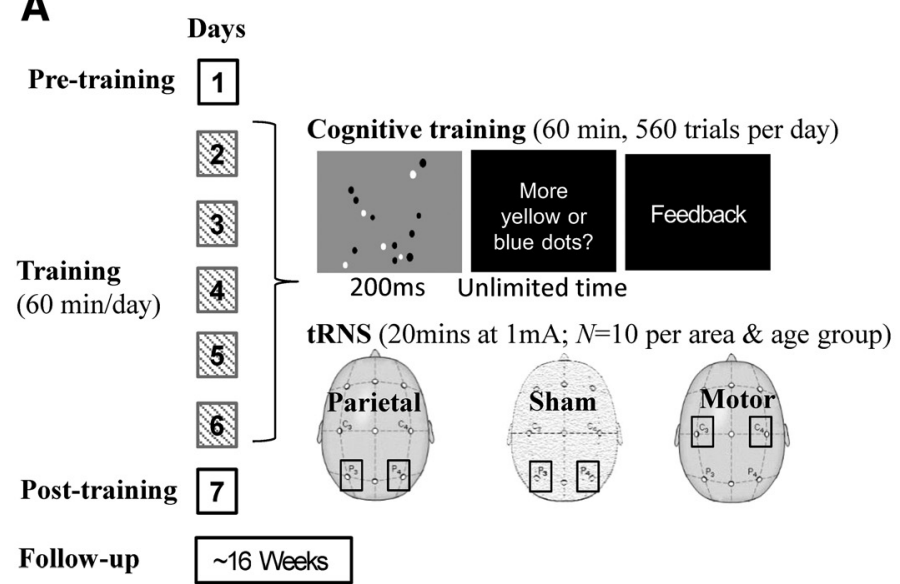

C

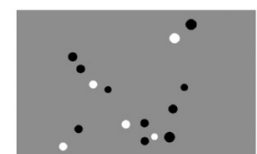

Congruent numerosity trials: numerosity and cumulative area correlate in the more numerous set. Cue-integration abilities are required for successful performance
B
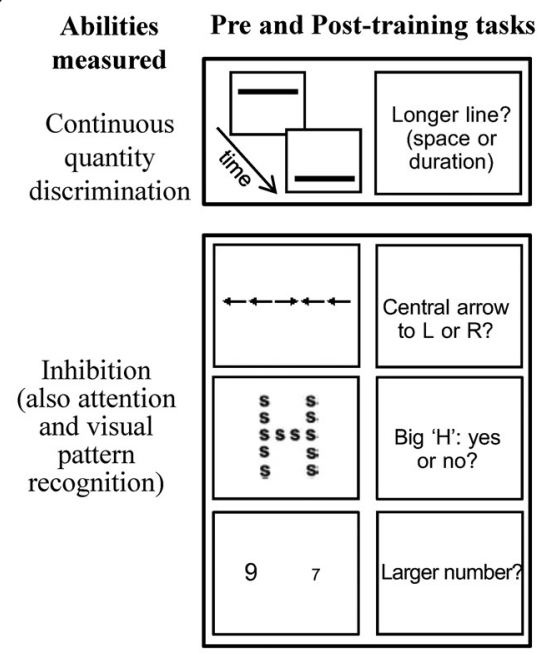

Arithmetic

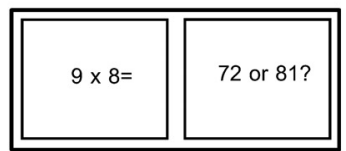

Figure 1. The training paradigm and the tasks used. A, All participants were trained for 5 consecutive days, i.e., days 2 to 6 , with a numerosity discrimination task while they received sham or real transcranial random noise stimulation (tRNS) to the parietal or motor areas (Training Only, Parietal tRNS + Training, Motor tRNS + Training). B, Before the training (Day 1, Pre-training), all participants were also tested with tasks assessing continuous quantity (time and space discrimination), inhibitory abilities, as well as attention, visual pattern recognition, and arithmetic. The same cognitive tasks were repeated at the end of the training (Day 7, Post-training) to test for any training-induced changes in performance. Possible long-term effects of training were tested at 16 weeks after training in participants who received parietal stimulation and training, and training only. $C$, The numerosity discrimination task used for training (with black and white dot stimuli for the purpose of the figure) allows distinguishing between congruent and incongruent numerosity trials. L, Left; $R$, right.

ity," i.e., the ability to judge the more numerous of two sets (Piazza et al., 2004; Cantlon et al., 2006; Halberda et al., 2008). We exploited the fact that stimulus numerosity inevitably correlates either positively with their cumulative area (congruent trials) or, if that is controlled, then negatively with their local size (incongruent trials) (Hurewitz et al., 2006; Gebuis and Reynvoet, 2012; Gilmore et al., 2013; Cappelletti et al., 2014). Although congruent numerosity trials require integrating information from distinct but concurrent visual cues (cue-integration abilities), uniquely incongruent numerosity trials require such integration alongside suppression of conflicting stimulus size cues (inhibitory abilities). We reasoned that, if brain stimulation coupled with training boosts different types of learning, differences in cue-integration versus inhibitory abilities may be observable, and this difference may be amplified by age, because inhibitory abilities tend to be poorer in aging participants (Hasher et al., 2007). Boosting numerosity or inhibitory abilities may also transfer onto other untrained processes or it may instead interfere with them if learning enhances conflicting resources for numerosity and these other processes.

\section{Materials and Methods}

\section{Participants}

Sixty right-handed human participants with normal or corrected-tonormal vision gave written consent and were paid to participate in our double-blind study, which was approved by the local ethics committee. Subjects were recruited according to exclusion criteria approved by the local ethics committee, which were the same as those used for transcranial magnetic stimulation studies. Participants were divided into two equal groups based on their age: (1) young participants $(n=30$; mean age, 24.4 years; range, $19-35$ years; 12 males); and (2) older participants ( $n=30$; mean age, 65.5 years; range, $60-73$ years; 13 males). Some data on young participants have been described previously (Cappelletti et al., 2013), but a novel and previously unreported series of analyses of these data are described here.

Participants in each age group were further divided in three subgroups depending on the type of stimulation received. In the main condition, younger and older participants underwent training on the numerosity discrimination task for 5 consecutive days while they received tRNS to parietal regions (parietal tRNS + training group, overall $n=20$; Fig. $1 \mathrm{~A}$ ). Results from this condition were compared against two control groups. In one of the control groups, young and older participants received no stimulation (sham) to the parietal regions during training (i.e., trainingonly group, overall $n=20$ ). This control condition served as a baseline to evaluate effects of tRNS on training. In a second control group, tRNS was delivered over the bilateral motor cortex during training in both age groups (motor tRNS + training, overall $n=20$ ). This control condition allowed us to test whether any training-induced effect was area specific or occurred regardless of which brain area was stimulated.

Across the three stimulation groups, subjects within each age group were overall matched for gender (older, $X_{(1)}^{2}=1.2, p=0.27$; younger: $\left.X_{(1)}^{2}=0.13, p=0.7\right)$, age (older, $F_{(2,29)}=0.9, p=0.4$; younger, $F_{(2,29)}=$ $0.33, p=0.72$ ), general education (older, $F_{(2,29)}=1.3, p=0.28$; younger, $\left.F_{(2,29)}=0.12, p=0.89\right)$, and mathematical education (older, $F_{(2,29)}=$ 
$0.16, p=0.85$; younger, $\left.F_{(2,29)}=2.2, p=0.14\right)$. Information on participants' education and mathematical education, the latter corresponding to the number of years during which participants formally learned mathematics at school, was collected to assess the possible influence of these factors on performance in the numerosity discrimination task.

\section{Stimulation design}

Following a standard procedure (Terney et al., 2008), tRNS was delivered by a battery-driven electrical stimulator (Version DC-Stimulator-Plus; NeuroConn) through two conductive rubber electrodes (size, $7 \times 5 \mathrm{~cm}$ ), covered with conductive gel and saline solution and positioned over the subject's scalp. On the basis of the standard 10-20 EEG procedure, the electrodes were positioned on the target areas corresponding to parietal (P3 and P4) or motor (C3 and C4 ) regions (Fig. 1A). The parietal and motor tRNS + training groups were stimulated with a random noise mode for 20 min with a fade in/out period of $20 \mathrm{~s}$, a current strength of $1000 \mu \mathrm{A}$, and a frequency of alternating current randomly selected from 0.1 to $640 \mathrm{~Hz}$, a safe intensity in healthy volunteers (Ambrus et al., 2010; Fertonani et al., 2011). The same parameters were used for the trainingonly (sham) group, but the stimulation consisted only of the fade in/out period (i.e., $40 \mathrm{~s}$ in total); although participants in this group did not receive full stimulation during training, they maintained the same setting as the participants in the other groups as if they were receiving stimulation (Ambrus et al., 2010; Fertonani et al., 2011). During the whole time course of the study, participants were not told whether they received real or sham stimulation, similar to other reported studies (Terney et al., 2008; Fertonani et al., 2011; Mulquiney et al., 2011; Cappelletti et al., 2013). Participants reported no discomfort or unusual sensation on their scalp.

\section{Experimental design}

All participants in all groups were trained for $1 \mathrm{~h}$ for 5 consecutive days (days 2-6) with the numerosity discrimination task (Fig. 1A, Training). In the tRNS + training group, this cognitive training coincided with parietal or motor stimulation. Before (Pre-training, Day 1) and after (Post-training, Day 7) the training, all participants were also tested with a series of tasks to assess quantity-based (time and space discrimination), inhibitory, and arithmetic abilities, as well as attention and visual pattern recognition (Fig. 1B). Participants in the parietal tRNS + training and training-only conditions were also tested $\sim 16$ weeks after training to assess any long-term effect of training and stimulation.

Stimulus presentation and data collection were controlled using the Cogent Graphics toolbox (http://www.vislab.ucl.ac.uk/Cogent) and MATLAB 7.11 software on a Sony PCG laptop computer with video mode of $640 \times 480$ pixels and $60 \mathrm{~Hz}$ refresh rate. During all testing sessions, participants sat in a quiet room under dimmed room lighting at a viewing distance of $57 \mathrm{~cm}$ from the monitor.

Training task: numerosity discrimination. For each training day, as well as before training, after training, and at follow-up, a parametrically designed task was used, which required participants to discriminate the numerosity of two sets of dot stimuli and measured in terms of Weber fraction ( $w f$; Halberda et al., 2008, 2012). A series of intermixed yellow and blue dots were each presented for $200 \mathrm{~ms}$ to participants who were instructed to make an unspeeded answer indicating which set contained more dots and were provided with feedback (Fig. 1A). At least 40 practice trials not included in the analysis were given to participants to familiarize them with the task. Each display contained 5-16 dots for each color such that the ratios between the larger and the smaller number of dots were $2: 1,4: 3,6: 5,8: 7,9: 8$, and 10:9. There were 40 trials for each of the easiest ratios (2:1 and 4:3), and 120 for each of the more difficult ratios (6:5, 8:7, 9:8, and 10:9), for a total of 560 trials presented in 10 blocks.

Based on an established design (Cappelletti et al., 2013, 2014), for each ratio, there was an equal number of randomly presented trials requiring either to integrate distinct but concurrent visual cues (congruent trials) or to suppress task-irrelevant information (incongruent trials). Congruent trials were those in which the most numerous set could be identified by judging quantitative changes in terms of number of dots (numerosity) or the total cumulative area covered by the dot stimuli, because these factors correlated. Correlation of numerosity and area was obtained by equalizing the average diameter of the dots in the larger set to the average diameter of the dots in the smaller set, such that in these congruent trials the cumulative area of the larger set was always larger than the cumulative area of the smaller one. The diameter of a dot ranged approximately between 0.57 and $1.17^{\circ}$ of visual angle from a distance of $57 \mathrm{~cm}$, with the average diameter being $0.87^{\circ}$. In contrast, incongruent numerosity trials were those in which the most numerous set consisted of dot stimuli with the smaller diameter, such that identifying this set required using an inhibitory strategy, i.e., ignore the fewer but larger and more salient dot stimuli belonging to the least numerous set (Fig. 1C). In these trials, the average diameter of the larger set (ranging from $\sim 0.57$ and $1.17^{\circ}$ of visual angle, i.e., $0.87^{\circ}$ of visual angle $\pm 35 \%$ ) was smaller than the average diameter of the smaller set (ranging from approximately $\pm 35 \%$ of the average diameter of the smaller set itself). The average diameter of the smaller set was selected so that the cumulative area of the two sets was equal. Although we cannot exclude that numerosity judgments may be based on a variety of strategies, cue integration and inhibition are thought to be commonly used (Gebuis et al., 2010; Gebuis and Reyvoet, 2012; Gilmore et al., 2013; Szúcs et al., 2013; Cappelletti et al., 2014).

Pretraining and posttraining tasks. We have explored previously whether training of numerosity discrimination may transfer to other types of quantity judgments and found that, in young participants, improved numerosity discrimination corresponded to improved performance in time and space processing (Cappelletti et al., 2013), reinforcing the idea that number, time, and space share common processes relying on parietal regions (Walsh, 2003; Bueti and Walsh, 2009; Cantlon et al., 2009; Cantlon, 2012). Here we aimed to test a new series of hypotheses, specifically whether such transfer may be influenced by any specific improvement in numerosity-based cue integration or inhibition, whether it may also concern untrained tasks probing inhibitory abilities, and whether transfer effects may be modulated by age.

As done previously (Cappelletti et al., 2013), time and space processing was assessed with an established two-choice discrimination paradigm tested formerly in young and elderly healthy participants and in neurological populations (Cappelletti et al., 2009, 2011; Lambrechts et al., 2013). Participants compared visual stimuli along the dimension of time or the orthogonal dimension of length. Stimuli were two horizontal white lines $\left(0.17^{\circ}\right.$ thickness) centered on the vertical meridian on a black background and presented sequentially one line $5.07^{\circ}$ above the horizontal meridian and the other $5.07^{\circ}$ below in random order (Fig. 1B). One line stimulus (the reference) was fixed (length of $10.2^{\circ}$ and duration of $600 \mathrm{~ms}$ ), whereas the other line (the test) could vary according to the method of constant stimuli in either length or duration, depending on the dimension to be judged (the irrelevant dimension always matched the reference). For each dimension, the ratio between the smaller and the larger stimulus could vary unpredictably over five levels (steps of $0.257^{\circ}$ for length and $40 \mathrm{~ms}$ for time) with equal frequency: 1.06, $1.13,1.2,1.27$, and 1.34 for time and 1.025, 1.05, 1.075, 1.10, and 1.125 for length. For each task, there were 200 observations presented in one block that contained 40 observations for each level of the test stimulus. Time and space tasks were run independently, with task order counterbalanced across participants and training sessions (before and after training) to avoid order effects.

Each trial began with a centrally displayed fixation point $\left(0.17^{\circ}\right.$ diameter) that remained visible until a key press from the participant and was immediately followed by the reference line, then by the test line and an interstimulus interval of $100 \mathrm{~ms}$. The screen then remained blank with the central fixation point until a response from the subject. The next trial immediately followed the response. In each task, participants made unspeeded responses by pressing either the up or down cursor arrow keys of the computer keyboard if either the upper or the lower line appeared the longest, in either duration or spatial extent. Correct answers were equally assigned to the up or down keys in each task. For each task, before the first experimental block, participants performed at least 20 practice trials that were not included in analysis.

Inhibitory abilities were measured with three well established tasks: the Stroop (word and number Stroop; Stroop, 1935; Henik and Tzelgov, 1982), a component of the attention network task (ANT; Fan et al., 2002), and the Navon task (Navon, 1977; Romei et al., 2011; tested in older participants only; Fig. $1 B$ ). Some of these tasks allowed us to also examine 
whether any stimulation effect may stretch over other more general abilities, such as attention or recognition of visual patterns. The latter was assessed with the Navon task in older participants and with a face sequential matching task (Pitcher et al., 2009) in younger participants. We used different tasks to probe visual pattern recognition in the two age groups because the Navon task may be a more sensitive paradigm to detect possible deficiencies in pattern recognition in the aging participants compared with face recognition. We expected no change in these abilities if the effect of stimulation and training was specific to quantity processing or inhibitory abilities.

The number Stroop task assesses the automatic processing of numbers and inhibitory processes using experimental stimuli that contain congruent and incongruent information (Henik and Tzelgov, 1982). In two separate tasks, participants viewed a total of 336 pairs of one to nine Arabic numbers ( 168 per task) that could vary in magnitude (e.g., 3 vs 2 ) or physical size (e.g., 3 vs 2 ). Therefore, there were three types of stimuli (each presented in 36 trials per each task): (1) a congruent stimulus corresponded to a pair of digits in which a given digit was larger in both the relevant and the irrelevant dimensions; (2) a neutral stimulus was a pair of digits that differed only on the relevant dimension (magnitude or physical size); and (3) an incongruent stimulus consisted of a pair of digits in which one of the digits was at the same time larger in one dimension (e.g., magnitude) and smaller in the other (e.g., physical size).

Participants were required to indicate with a key press the larger number in either magnitude or physical size (in different blocks). After a 500 ms fixation cross, the number stimuli were presented until the participant made an answer or for a maximum of $4000 \mathrm{~ms}$. After this, the next fixation cross appeared, and the following trial started immediately. For each task (magnitude or physical size), accuracy and response times (RTs) were recorded.

Aging participants were also tested with an additional Stroop task, the word Stroop (Stroop, 1935). This required either to read as quickly as possible a word ignoring the color of the ink it is printed in (for instance "RED" whether printed in the color red, blue, or gray for a neutral condition) or to name the color in which the word stimuli are printed, ignoring their meaning (for instance, to name the color red whether displayed on the word "RED," "BLUE," or "XXX" for a neutral condition). There were 60 trials for each task (word or color). Stimuli were the word RED, BLUE, or XXX (the latter for the color Stroop only). These could appear in the color red, blue, or gray (color Stroop only), therefore resulting in a congruent, incongruent, or neutral condition (20 trials for each type and each task), depending on whether, for example, the color red appeared on the word RED, on the word BLUE, or on the string XXX.

In each trial, participants saw a centrally presented $500 \mathrm{~ms}$ fixation cross, followed by a word stimulus displayed until the participant made an answer or for a maximum of $4000 \mathrm{~ms}$. After this, the following trial started immediately. Participants were asked to decide as quickly as possible with a key press whether the stimulus was the word RED or BLUE regardless of the color (in the word task) or whether it was displayed in red or blue font regardless of the meaning of the word (color task). The two tasks were presented separately, and the order of the tasks was counterbalanced across participants. For each task (word or color), accuracy and RTs were calculated for the three conditions (neutral, congruent, and incongruent).

In the ANT (Fan et al., 2002), a cuing task and a flanker task were combined such that participants responded to cued or uncued central targets while ignoring flanking distractors. A total of 288 trials were presented in three consecutive blocks of 96 trials each. The stimuli consisted of a target arrow flanked by two arrows on either side, which could appear in the same direction as the target arrow (congruent condition, e.g., $\leftarrow \leftarrow \leftarrow \leftarrow \leftarrow$ ) or in the opposite direction (incongruent condition, e.g., $\leftarrow \leftarrow \rightarrow \leftarrow \leftarrow$ ). Each arrow was presented at $0.55^{\circ}$ of visual angle and separated from the adjacent arrows by $0.06^{\circ}$ of visual angle; the stimuli (the central arrow and the four flankers) consisted of $3.08^{\circ}$ of total visual angle. Participants were instructed to attend to the middle arrow and to decide whether it was pointing to the left or to the right. A trial consisted of the following events: a central fixation cross was first presented for a random duration between 400 and $1600 \mathrm{~ms}$, followed by either a $100 \mathrm{~ms}$ warning asterisk cue in the cued trials or by a longer fixation in the uncued trials, and then followed by a second $400 \mathrm{~ms}$ fixation period, after which the target and the flankers appeared simultaneously and centrally at $1.06^{\circ}$ of visual angle either above or below the fixation point. The cue could appear centrally, hence corresponding to a spatially neutral condition, or it could precede the target and flankers in the same position (the cue was always valid), i.e., at $1.06^{\circ}$ of visual angle above or below the fixation point, which corresponded to a spatially orienting condition. The target and flankers remained on the screen until the participant responded or for a maximum of $1700 \mathrm{~ms}$. After a response was made, the next trial began immediately. Participants had to press as quickly as possible a left-hand key if the central arrow pointed left and a right-hand key if it pointed right. The task allows measuring three indexes of performance based on how RTs of correct answers are influenced by alerting cues, spatial cues, and flankers: (1) alertness (cued vs uncued trials); (2) orienting (central cue vs spatial cue); and (3) conflict (congruent vs incongruent trials averaged across cued and uncued and central vs spatial cue).

In the Navon task, participants were presented with a $1.5 \mathrm{~s}$ centrally presented white fixation point, followed by a 200 ms black background and by a $500 \mathrm{~ms}$ visual stimulus centered at fixation. Following previous studies (Mevorach et al., 2006; Romei et al., 2011) stimuli consisted of the orthogonal combination of the letters " $\mathrm{H}$," "S," or "D" at the global level (height, $8.26^{\circ}$; width, $5.38^{\circ}$ ), and multiple red and white alternating $\mathrm{H}, \mathrm{S}$, or D letters at the local level (height, $1.34^{\circ}$; width, $1.06^{\circ}$ ). At the global and local levels, letter stimuli could be either congruent (a big letter $\mathrm{H}$ made of small $\mathrm{H}$ letters) or incongruent (a big letter $\mathrm{H}$ made of small S letters; 160 trials per each stimulus). Participants were instructed to indicate with a key press whether the target letter $\mathrm{H}$ was or not present at either the local or global level in two different blocks each made of five shorter sub-blocks. Speed and accuracy were both stressed in the instructions.

Finally, we tested symbolic arithmetical abilities following the proposal that they may be linked to number acuity (Halberda et al., 2008; but see Butterworth, 2010). However, we predicted no significant trainingrelated changes in arithmetic performance because it is based on additional cognitive resources, such as memory and executive abilities, which were not trained. Participants verified the result of arithmetical problems based on single-digit operands presented in two equivalent series of 54 single-digit addition, subtraction, and multiplication problems in separate short blocks of 18 trials each, with one series presented at pretraining and one at posttraining to avoid effects simply deriving from practice with the task. Each problem was displayed with two one- or two-digit answers, one of which was correct while the other was one, two or three units apart from the correct answer $(3 \times 4=12$ or 15 ? $)$.

Tasks at pretraining and posttraining were administered in pseudorandom order to participants in all age groups and stimulation groups such that tasks with longer blocks (time, space, numerosity discrimination, and ANT) were interleaved with tasks with shorter blocks (arithmetic, Navon, and Stroop). Randomly selected tasks with short and longer blocks were administered in alternation to avoid overloading participants and to ensure that any training or age-related effects are not instead attributable to task order.

\section{Data analyses}

Following previous studies (Halberda et al., 2008, 2012; Cappelletti et al., 2013 , 2014), for each participant, response distributions in the numerosity discrimination task were used to estimate the precision of the underlying numerical representation, expressed as $w f$ (Halberda et al., 2008). The $w f$ determines the variation of the SD of the Gaussian random variables in each numerosity. The difference between the two Gaussian variables (i.e., the Gaussian of the set with the larger numerosity minus the Gaussian of the set with the smaller numerosity) returns a new Gaussian random variable $\left[\mathrm{G}_{(n 2-n 1)}\right]$ with mean $n_{2}-n_{1}$ and SD wf $\sqrt{n_{1}^{2}+n_{2}^{2}}$. The larger the $\mathrm{SD}$ of $\mathrm{G}_{(n 2-n 1)}$, the larger is the overlap of the two Gaussian distributions representing the numerosity of the two sets and in turn the more difficult it is to discriminate between them. Therefore, the larger the $w f$, the worse the performance in the numerosity discrimination task, and the smaller the $w f$, the better the performance. A similar procedure was used to calculate the $w f$ for the time and space discrimination tasks.

For all the other tasks, we used an index of accuracy (percentage correct) and/or speed (RTs) of correct answers cleaned for 2 SDs above the 
A

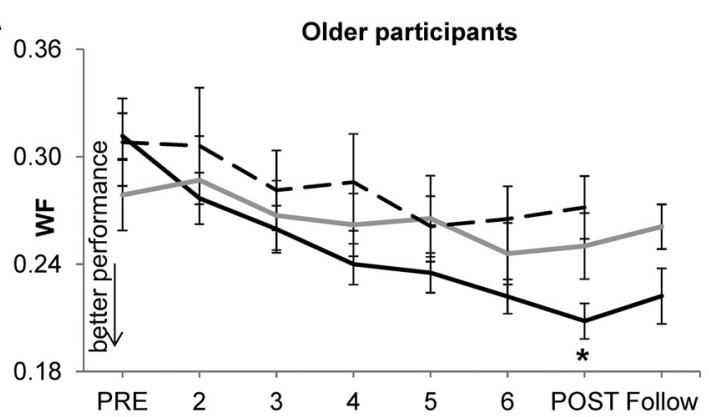

(1)

C

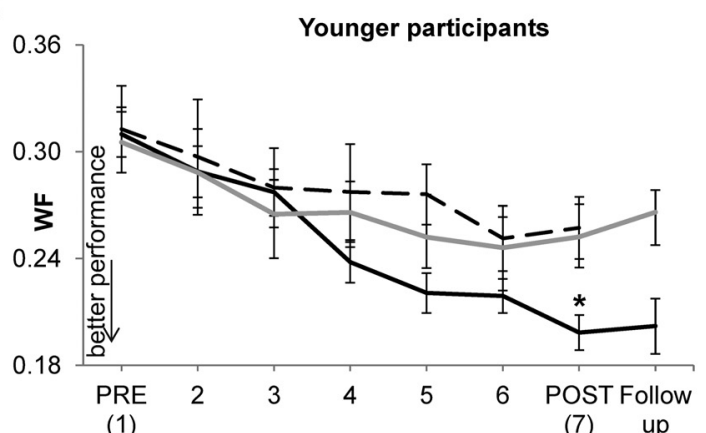

B

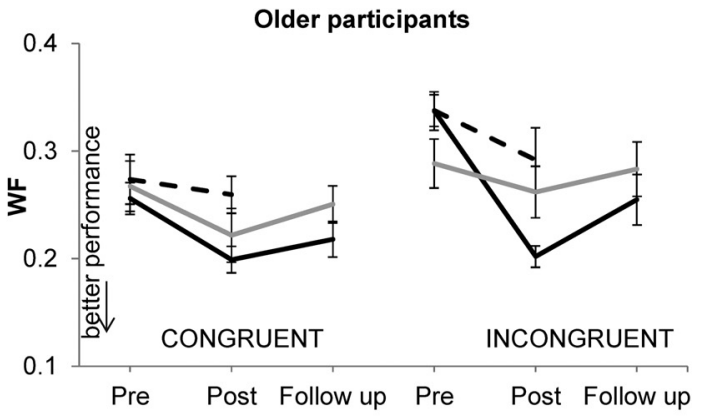

D

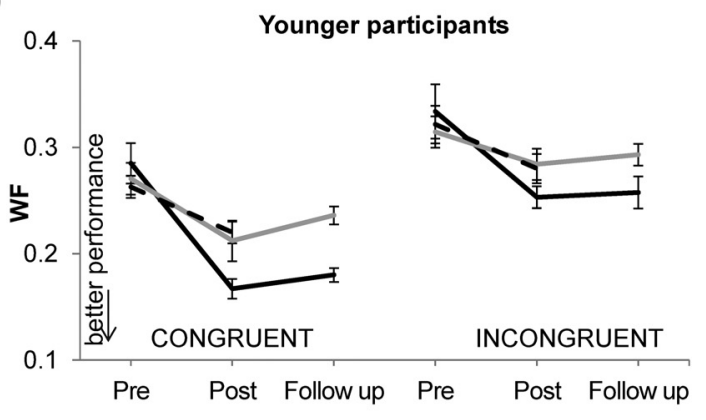

— Parietal tRNS+Training — Sham tRNS+Training - - Motor tRNS+Training

Figure 2. Effects of numerosity training. Performance in the three stimulation groups expressed as Weber Fraction (WF) in the numerosity discrimination task at pretraining, posttraining, during each of the training days (2 to 6), and at 16 weeks follow-up in older $(\boldsymbol{A})$ and younger ( $\boldsymbol{C}$ participants and specific for congruent and incongruent numerosity trials in the two age groups ( $\boldsymbol{B}$ and $\boldsymbol{D}$, respectively). Bars are SEs, and asterisks indicate significant differences in performance $(p<0.001)$.

mean for each task and participant (removing between 0 and $3.4 \%$ of the data in young participants and $4.4 \%$ in older participants). The data were analyzed using ANOVAs and $t$ test with Sidak's correction for multiple comparisons, with a $p<0.05$ considered significant for all statistical analyses. The data sphericity was tested using the Mauchly's test when appropriate. If the sphericity test results were statistically significant, the data were corrected using Huynh-Feldt correction.

\section{Results}

\section{Effect of cognitive training and tRNS on number acuity}

At pretraining, numerosity discrimination did not differ across stimulation groups in younger $\left(F_{(2,29)}=0.02, p=0.98\right)$ or older $\left(F_{(2,29)}=0.7, p=0.49\right)$ participants. Training-induced changes were measured in a repeated-measures ANOVA with the $w f$ values of training (pre and post) as a within-subjects factor and age group (young vs older) and stimulation group (parietal tRNS + training, training only, and motor tRNS + training) as betweensubjects factors. Across age groups, number acuity improved significantly after training $\left(F_{(1,54)}=70.7, p<0.001\right)$, with $w f$ changing from $0.304 \pm 0.014$ to $0.239 \pm 0.011$ (mean $\pm \mathrm{SE}$ ), corresponding to $\sim 19.6 \%$ enhancement. This improvement was similar in the two age groups (no significant three-way interaction between training, age group, and stimulation group, $F_{(2,54)}$ $=0.21, p>0.8 ; w f$ change: younger, from $0.309 \pm 0.016$ to $0.236 \pm 0.013$; older, from $0.299 \pm 0.022$ to $0.243 \pm 0.017)$ and did not depend on the participants' education or mathematical education (education, $b=0.03, \mathrm{SE}=0.003, t=0.21, p=0.8$; mathematical education, $b=0.013, \mathrm{SE}=0.004, t=0.1, p=$ 0.92).

Training-induced performance in numerosity discrimination differed depending on the stimulation group (significant interaction between training and stimulation group, $F_{(2,54)}=7.3, p=$
0.002). Specifically, across age groups, a significant increase in performance was observed when training was coupled with parietal stimulation $[w f$ from $0.3106 \pm 0.026$ to $0.2033 \pm 0.012$ (mean $\pm \mathrm{SE}$ ), corresponding to $32.5 \%$ improvement; $t_{(19)}=6.3$, $p<0.001$ ] and also after training alone ( $w$ ffrom $0.292 \pm 0.022$ to $0.251 \pm 0.015$, corresponding to a $11.8 \%$ improvement; $t_{(19)}=$ $3.1, p=0.005$ ) and training coupled with motor tRNS ( $w$ f from $0.3103 \pm 0.026$ to $0.2644 \pm 0.025$, corresponding to $14.5 \%$ improvement; $t_{(19)}=5.8, p<0.001$; Fig. $\left.2 A, C\right)$. However, across age groups, training coupled with parietal stimulation resulted in a significantly larger improvement compared with training only $\left(t_{(38)}=3.4 p=0.002\right)$ and with training coupled with motor stimulation $\left(t_{(38)}=3.6, p=0.001\right)$; improvements after training only and training + motor stimulation did not differ $\left(t_{(38)}=\right.$ $0.37, p=0.7)$. No other effects reached significance.

Next, we examined to what extent pretraining performance influenced training-induced changes because, in each age group and across stimulation groups, initial performance in numerosity discrimination correlated with posttraining change (younger, $r=0.6, p<0.001$; older, $r=0.65, p<0.001$ ). Separate univariate ANOVAs were run in each age group with $w f$ of the difference between pretraining and posttraining performance as the dependent variable, the stimulation group as the fixed factor, and the $w f$ of pretraining performance as the covariate. In aging participants, there was a significant difference between stimulation groups $\left(F_{(2,26)}=9.1, p=0.001\right)$, indicating that, even after taking into account initial performance, improvement in number acuity was significantly higher after parietal tRNS + training compared with training only and motor tRNS + training (Helmert contrasts, $\left.t_{(1)}=0.63, p<0.001\right)$ and with no difference between training only and motor tRNS + training $\left(t_{(1)}=0.08, p=0.6\right)$. 
Likewise, in younger participants, a significant difference between stimulation groups emerged $\left(F_{(2,26)}=5.8, p<0.01\right)$, such that, even after taking into account pretraining performance, improvement in number acuity was significantly higher after parietal tRNS + training compared with training only and motor tRNS + training (Helmert contrasts, $\left.t_{(1)}=0.62, p=0.002\right)$ and with no difference between training only and motor tRNS + training $\left(t_{(1)}=0.01, p=0.9\right)$.

We also examined whether the effect of training and stimulation was long lasting by comparing participants' performance in numerosity discrimination (indexed by $w f$ ) at immediate posttraining and 16 weeks after training in each age group (younger and aging) and each stimulation group that was tested long term (parietal tRNS + training and training only). In aging participants, performance in the numerosity discrimination task in the parietal tRNS + training group remained unchanged 16 weeks after training (no difference with immediate posttraining, $t_{(9)}=$ $1.1, p=0.3$ ), and it differed significantly from pretraining performance $\left(t_{(9)}=5.8, p<0.001\right)$. In contrast, in the training-only group, posttraining changes in number acuity declined over time, such that number acuity at pretraining and at 16 weeks after training did not differ significantly $\left(t_{(9)}=0.8, p=0.44\right.$; Fig. $\left.2 A\right)$. In younger participants, posttraining improvement in the numerosity discrimination task in the parietal tRNS + training group remained stable up to 16 weeks after training (no difference with immediate posttraining, $t_{(9)}=0.3, p=0.8$ ), and it still differed from initial performance $\left(t_{(9)}=3.4, p<0.01\right)$. In contrast, in the training-only group, posttraining improvement in number acuity declined over time such that performance at pretraining did not differ significantly from performance at 16 weeks after training $\left(t_{(9)}=1.5, p=0.2\right.$; Fig. $\left.2 C\right)$.

These results suggest that, in both age groups, the improvement in number acuity we observed after training was maintained long term only when training was combined with parietal stimulation.

\section{Effect of cognitive training and tRNS on learning cue integration versus inhibition}

At pretraining, congruent and incongruent numerosity trials did not differ in the two age groups (congruent, $t_{(58)}=1.1, p=0.2$; incongruent, $\left.t_{(58)}=1.5, p=0.1\right)$. However, some of the elderly participants ( $n=6$ of $30, n=2$ in each stimulation group) performed exceptionally well in the incongruent numerosity trials (1 SD higher than younger participants). Disregarding these elderly participants, there was a significant difference in the incongruent but not the congruent numerosity trials in the two age groups $\left(t_{(52)}=2.3, p=0.02\right.$ and $t_{(52)}=1.0, p=0.3$, respectively), similar to previous results (Cappelletti et al., 2014).

To test for any differences in $w f$ between numerosity trials requiring cue-integration versus inhibitory abilities, we ran a repeated-measures ANOVA including all participants, with training (pre and post) and trial type ( $w f$ of congruent and incongruent numerosity trials) as within-subjects factors and age group (older and younger) and stimulation group (parietal tRNS + training, training only, and motor tRNS + training) as between-subjects factors. This showed a significant main effect of training $\left(F_{(1,54)}=88.03, p<0.001\right)$ and trial type $\left(F_{(1,54)}=57.5\right.$, $p<0.001)$; there were also significant interactions between: training and stimulation group $\left(F_{(2,54)}=10.26, p<0.001\right)$; training, trial type, and stimulation group $\left(F_{(1,54)}=8.9, p=0.004\right)$; and training, trial type, stimulation group, and age group $\left(F_{(2,54)}\right.$ $=3.4, p=0.042$ ). To better understand this four-way interac- tion, the effects of training and trial type were analyzed in each age group separately.

\section{Aging participants}

In aging participants, an ANOVA with the same factors as above showed a significant effect of training $\left(F_{(1,27)}=29.03, p<0.001\right)$, because performance in this age group overall increased by $\sim 17 \%$ ( $w f$ from $0.299 \pm 0.022$ at pretraining to $0.243 \pm 0.017$ at posttraining, mean $\pm \mathrm{SE}$ ).

Trial type was also significant $\left(F_{(1,27)}=15.2, p=0.001\right)$ because posttraining $w f$ was higher for incongruent than congruent numerosity trials ( $w f$ of 0.29 vs 0.243 ). The interaction between training and stimulation group was significant $\left(F_{(2,27)}=4.33\right.$, $p=0.02)$. Performance in numerosity discrimination increased significantly in the parietal tRNS + training group $31.5 \%$ increase, $w f$ from $0.311 \pm 0.022$ at pretraining to $0.208 \pm 0.009$ at posttraining, mean $\left.\pm \mathrm{SE} ; t_{(9)}=4.6, p=0.001\right)$ and the motor tRNS + training group $(13.2 \%$ increase, $w$ from $0.313 \pm 0.026$ at pretraining to $0.271 \pm 0.017$ at posttraining; $t_{(9)}=2.8, p=0.02$ ) but not in the training-only group $(8.8 \%$ increase, $w f$ from $0.279 \pm 0.019$ at pretraining to $0.25 \pm 0.018$ at posttraining; $t_{(9)}$ $=1.7, p=0.1$ ).

The three-way interaction between training, trial type, and stimulation group was significant $\left(F_{(2,27)}=3.9, p=0.03\right)$. In the parietal tRNS + training group, performance improved significantly depending on trial type $\left(F_{(1,9)}=20.5, p=0.001\right)$. Specifically, in this group, number acuity improved in both the congruent numerosity trials $(19.5 \%$ increase, $w f$ from $0.256 \pm$ 0.022 at pretraining to $0.202 \pm 0.012$ at posttraining, mean $\pm \mathrm{SE}$; $\left.t_{(9)}=3.1, p=0.01\right)$ and the incongruent trials $(40.1 \%$ increase, $w f$ from $0.337 \pm 0.018$ at pretraining to $0.199 \pm 0.009$ at posttraining; $\left.t_{(9)}=11.3, p<0.001\right)$, with a significant difference in improvement between the two trial types $\left(t_{(9)}=4.5, p=0.001\right)$. This interaction was not present in the motor tRNS + training group $\left(F_{(1,9)}=1.1, p=0.3\right)$ because performance increased but not significantly in the congruent numerosity trials $\left(t_{(9)}=0.5\right.$, $p=0.6)$ and in the incongruent trials $\left(t_{(9)}=1.8, p=0.1\right)$. Likewise, in the training-only group, number acuity did not change significantly as a function of trial type $\left(F_{(1,9)}=0.4, p=0.5\right)$; again, there was an increase, but not a significant one in performing both the congruent $\left(t_{(9)}=2.0, p=0.5\right)$ and incongruent $\left(t_{(9)}\right.$ $=1.2, p=0.3$ ) numerosity trials (Fig. $2 B$ ).

Additional analyses examined whether any of the significant changes observed for congruent and incongruent numerosity trials were maintained over time. In the parietal tRNS + training group, 16-week posttraining changes in congruent trials remained unchanged from posttraining performance $\left(t_{(9)}=0.87\right.$, $p=0.4)$ and differed significantly from pretraining $\left(t_{(9)}=3.1\right.$, $p<0.02)$. Likewise, changes in incongruent trials at 16 weeks after training were still maintained relative to before training $\left(t_{(9)}\right.$ $=4.0, p=0.003)$, although performance in these trials changed significantly from immediate post-training $\left(t_{(9)}=2.8, p<0.02\right)$. In the training-only group, 16-week posttraining changes in congruent trials were not significantly different from pretraining performance $\left(t_{(9)}=0.5, p=0.6\right)$, and likewise changes in incongruent trials at 16 weeks after training also did not differ relative to immediately after training $\left(t_{(9)}=0.1, p=0.9\right)$. Note that for both trials, performance at 16 weeks after training did not differ from immediate post-training (congruent, $t_{(9)}=1.5, p=$ 0.2 ; incongruent, $t_{(9)}=0.6, p=0.6$ ), but rather than reflecting a stable improvement, this indicates that training-related enhancement was only modest and with no subsequent change (Fig. 2B). 


\section{Younger participants}

In younger participants, an ANOVA with the same factors as in the analysis of the aging group showed a significant effect of training $\left(F_{(1,27)}=73.6, p<0.001\right)$ because performance in this group overall increased by $\sim 22 \%$ ( $w f$ from $0.309 \pm 0.016$ at pretraining to $0.236 \pm 0.013$ at posttraining, mean $\pm \mathrm{SE})$. Trial type was also significant $\left(F_{(1,27)}=50.2, p<0.001\right)$ because posttraining $w f$ was higher for incongruent than congruent numerosity trials ( $w f$ of 0.2857 vs 0.2348 ). The interaction between training and stimulation group was significant $\left(F_{(2,27)}=6.7, p=\right.$ $0.004)$. The improvement in performance was higher in the parietal tRNS + training group $(33.6 \%$ increase, $w f$ from $0.310 \pm$ 0.02 at pretraining to $0.198 \pm 0.01$ at posttraining; $t_{(9)}=7.4, p<$ $0.001)$ compared with the motor tRNS + training group $(19.3 \%$ increase, $w f$ from $0.313 \pm 0.03$ at pretraining to $0.257 \pm 0.03$ at posttraining; $\left.t_{(9)}=4.1, p=0.003\right)$ and with the training only group ( $14.8 \%$ increase, $w f$ from $0.305 \pm 0.024$ at pretraining to $0.252 \pm 0.013$ at posttraining; $t_{(9)}=2.5, p<0.03$; Fig. $2 C$ ) Improvement after training alone or training coupled with motor stimulation did not differ $\left(t_{(18)}=0.6, p=0.5\right)$.

The interaction of training and trial type was significant $\left(F_{(2,27)}=4.0, p=0.05\right)$; this is because, across stimulation groups, training improved performance in the congruent numerosity trials $(26.8 \%$ increase, $w f$ from $0.273 \pm 0.008$ at pretraining to $0.199 \pm 0.008$ at posttraining; $\left.t_{(29)}=6.9, p<0.001\right)$ and the incongruent trials $(15.7 \%$ increase, $w f$ from $0.3232 \pm 0.011$ at pretraining to $0.272 \pm 0.008$ at posttraining; $t_{(29)}=5.2, p<$ $0.001)$, with a significant difference between these trial types $\left(t_{(29)}\right.$ $=2.0, p=0.05$ ). Improvement in the two types of trial did not differ between the stimulation groups (no significant three-way interaction between training, trial type, and stimulation group, $F_{(2,27)}=0.9, p=0.4$; Fig. $\left.2 D\right)$.

Additional analyses examined whether any of the changes observed for congruent and incongruent numerosity trials were longstanding. In the parietal tRNS + training group, improvement in congruent trials at 16 weeks after training remained unchanged from immediately after training performance $\left(t_{(9)}=1.6\right.$, $p=0.1)$ and differed significantly from before training $\left(t_{(9)}=\right.$ $5.4, p<0.001)$. Likewise, changes in incongruent trials at 16 weeks after training were stable relative to immediate posttraining performance $\left(t_{(9)}=0.3, p=0.8\right)$, and long-term performance was also maintained compared with pretraining $\left(t_{(9)}=\right.$ $3.1, p<0.02$ ). In the training-only group, 16 -week posttraining changes in congruent trials were not significantly different from pretraining performance $\left(t_{(9)}=1.1, p=0.3\right)$, and likewise changes in incongruent trials at 16 weeks after training did not differ relative to before training $\left(t_{(9)}=1.5, p<0.2\right)$. Note that, for both trials, performance at 16 weeks after training did not differ from immediately after training (congruent, $t_{(9)}=2.1, p=0.7$; incongruent, $\left.t_{(9)}=0.2, p=0.9\right)$, but rather than reflecting a stable improvement, this indicates that there was little enhancement after training with no additional change (Fig. 2D).

Overall, these analyses highlight two main results. Regardless of age, the largest improvement in number acuity was achieved by simultaneously combining cognitive training with parietal stimulation. Despite no age-related quantitative differences in learning, improvement in the two age groups differed in the content of learning: older participants' improved performance was driven by a significantly larger enhancement in numerosity trials requiring inhibitory abilities relative to cue integration, especially after parietal stimulation coupled with training. In contrast, younger participants improved significantly more in cue integration rather than in inhibitory abilities. Moreover, in both age groups, training associated with parietal stimulation resulted in the most robust long-term changes in both congruent and incongruent trials relative to training only.

\section{Transfer of trained abilities to other cognitive abilities}

Continuous quantity processing (space and time discrimination) We showed previously that in young participants improvements in number acuity after parietal stimulation and number training transferred onto other untrained but related abilities, specifically continuous quantity processing such as time and space (Cappelletti et al., 2013). Here we tested the new hypothesis that changes in cue integration and inhibitory abilities may differentially affect continuous quantity processing. We reasoned that improvements in cue integration may correspond to improvements in time and space discrimination because both numerosity and space/time discrimination require quantity manipulation likely to rely on parietal regions (Walsh, 2003; Bueti and Walsh, 2009; Cantlon et al., 2009; Cantlon, 2012). In contrast, improvements in inhibitory abilities may reflect enhanced suppression of taskirrelevant information in the form of continuous quantity, for instance, in terms of the cumulative area covered by the larger dot stimuli. Inhibiting continuous quantity information may be detrimental for time and space discrimination whose processing is based on the ability to differentiate between two continuous quantity stimuli.

Time and space discrimination did not differ across stimulation groups at pretraining (younger, $F_{(2,29)}=0.1, p=0.9$ and $F_{(2,29)}=0.41, p<0.7$; older, $F_{(2,29)}=0.23, p=0.97$ and $F_{(2,29)}=$ $0.16, p<0.85$, for space and time, respectively). Traininginduced changes in time and space processing were tested in separate repeated-measures ANOVAs with the $w f$ values of training (before and after) for each task as a within-subjects factor and age group (younger and older) and stimulation group (parietal tRNS + training, training only, and motor tRNS + training) as between-subjects factors.

These analyses showed that performance in space discrimination changed significantly from pretraining depending on age (significant interaction of training and age group, $F_{(1,54)}=3.8$, $p=0.05)$ and in opposite directions: in younger participants, space discrimination improved $(9.8 \%$ increase; pretraining vs posttraining $\left.w f, F_{(2,29)}=4.3, p<0.001\right)$, whereas in older participants, it decreased $(7.9 \%$ decrease; pretraining vs posttraining $w f, F_{(2,29)}=-1.5, p=0.05$; Fig. $\left.3 A\right)$.

As well as on age group, changes in space discrimination depended on the type of stimulation received (significant interaction of training, age group, and stimulation group, $F_{(2,54)}=3.9$, $p<0.03)$. Additional separate analyses for each age group and with the same factors as in the previous analysis indicated that in younger participants performance was modulated by the type of training received (significant interaction between training and stimulation group, $\left.F_{(2,27)}=3.3, p<0.05\right)$. Specifically, performance in space discrimination improved significantly after parietal tRNS + training $\left(18 \%\right.$ increase; $\left.t_{(9)}=5.6, p<0.001\right)$ but not training only $\left(t_{(9)}=0.9, p=0.3\right)$ or motor tRNS $+\operatorname{training}\left(t_{(9)}=\right.$ 3.4, $p=0.7)$.

Similarly, in the older group, performance in space discrimination changed depending on the type of stimulation received (interaction between training and stimulation group, $F_{(2,27)}=$ 3.0, $p=0.06$ ), and specifically it decreased significantly after parietal tRNS + training $\left(26 \%\right.$ decrease; $\left.t_{(9)}=2.2, p=0.05\right)$ but not in the training-only $\left(t_{(9)}=-0.7, p=0.5\right)$ or motor tRNS + training $\left(t_{(9)}=0.4, p=0.7\right.$ ) groups (Fig. $3 A$ ). Additional analyses tested whether any of the significant changes found for space 


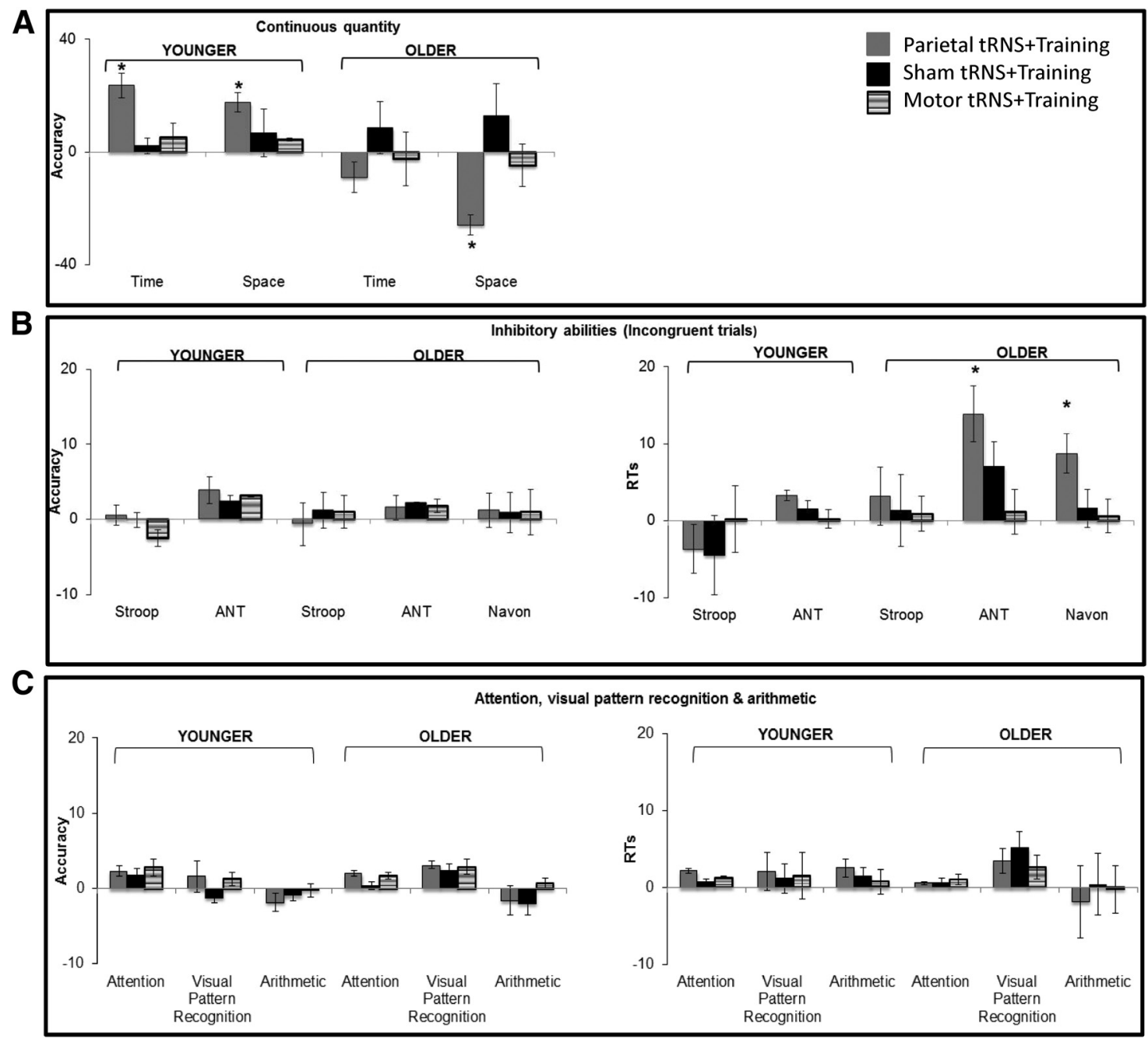

Figure 3. Transfer of learning to untrained tasks. Performance of older and younger participants in the three stimulation groups expressed as percentage change from pretraining accuracy (wf or correct answers) and response times (RTs). $\boldsymbol{A}$, Continuous quantity (time and space discrimination). $\boldsymbol{B}$, Inhibitory abilities. $\boldsymbol{C}$, Attention, visual pattern recognition, and arithmetic. Changes in inhibitory abilities focus on performance in incongruent trials in three tasks used [Stroop (averaged across number, physical, word, and color), ANT, and Navon]. Attention index combines cued and uncued, spatially and centrally oriented trials; visual pattern recognition merges performance in global and local-feature stimuli; arithmetic reflects average performance across the three types of problems used (addition, subtraction, and multiplication). Bars are SEs, and asterisks indicate significant differences in performance relative to pretraining $(p<0.05$ or $p<0.001)$. Note that, for convenience of comparison with accuracy, the data on RTs have been sign inverted (i.e., negative values transformed to positive and vice versa), so that higher values correspond on the graph to better, rather than poorer, performance.

discrimination in the parietal tRNS + training group were long term. Performance at 16 weeks after training changed from immediately after training but was still lower (i.e., higher $w f$ ) than before training, although not significantly $\left(t_{(9)}=1.1, p=0.3\right.$ and $t_{(9)}=0.3, p=0.8$, respectively). This suggested that, with time, space discrimination tended to return to the initial level of performance, although it was not the same as at pretraining.

Equivalent analyses on time discrimination showed that performance in this task also changed significantly from pretraining depending on age (significant interaction of training and age group, $\left.F_{(1,54)}=17.6, p<0.001\right)$ and again in opposite directions: in younger participants, time discrimination improved $(12.4 \%$ increase; pretraining vs posttraining $\left.w f, F_{(2,29)}=2.8, p=0.05\right)$, whereas in older participants, it decreased but not significantly (6.1\% decrease; pretraining vs posttraining $w f, F_{(2,29)}=1.9, p=$ 0.1 ). An additional analysis was performed in the younger group with the $w f$ values of performance in time discrimination (before and after training) as within-subjects factors and stimulation group (parietal tRNS + training, training only, and motor tRNS
+ training) as between-subjects factor. This showed a significant main effect of training $\left(F_{(1,27)}=11.7, p=0.002\right)$ and a significant interaction of training and stimulation group $\left(F_{(2,27)}=3.4, p<\right.$ $0.05)$. This interaction reflected improved performance that was only significant in the parietal tRNS + training group (23\% increase; $\left.t_{(9)}=5.2, p=0.001\right)$ but not in the training-only $\left(t_{(9)}=\right.$ $0.3, p=0.7)$ or motor tRNS + training $\left(t_{(9)}=2.0, p=0.09\right)$ groups (Fig. $3 A$ ).

Regardless of the stimulation group, training-related changes in space discrimination were significantly higher than changes in time discrimination in aging participants ( $w f$ difference between pretraining and posttraining, $\left.t_{(29)}=12.9 p<0.001\right)$ but not in younger participants ( $w f$ difference between pretraining and posttraining, $t_{(29)}=1.2 p<0.2$ ).

Overall, these results suggest that, in the two age groups, performance in space discrimination was modulated by number training coupled with stimulation but in opposite ways: an increase in performance was found in younger participants who received training and parietal Stimulation, but a decrease in per- 
formance emerged in older participants who underwent the same type of training. A similar but not significant trend to negative transfer was observed in aging participants' time discrimination. The exact reasons for this lack of significance are difficult to establish with the current data; one possibility to be further explored could be that in the case of time processing the inhibition of continuous quantity induced by the training was attenuated by other cognitive processes, such as attention or memory that are needed particularly in time discrimination (Walsh, 2003).

\section{Inhibitory abilities}

These were measured in three tasks: (1) Stroop (word/color and physical/number); (2) a component of the ANT; and (3) the Navon task. The specific analyses for each of these tasks are reported below.

Stroop tasks. At pretraining, performance across stimulation groups did not differ in the two age groups in any of the Stroop tasks (younger, all $p$ values $>0.9$; older: all $p$ values $>0.8$ ). For each age group, separate ANOVAs were run for each Stroop task (word, color, number, and physical), with training (pre and post) and RT or accuracy (in independent analyses) of the different Stroop trials (congruent, neutral, and incongruent) as withinsubjects factors and stimulation group (parietal tRNS + training, training only, and motor tRNS + training) as between-subjects factor.

In the younger group, accuracy did not change significantly in any of the Stroop tasks after training and regardless of stimulation group (all $p$ values $>0.9$ ). A similar analysis on RTs revealed a main effect of stimulus (RTs averaged across pretraining and posttraining: $431 \mathrm{~ms}$ for incongruent, $406 \mathrm{~ms}$ for neutral, $377 \mathrm{~ms}$ for congruent, $\left.F_{(2,54)}=129.49, p<0.001\right)$ in the number Stroop, as well as a main effect of stimulus (RTs averaged across pretraining and posttraining: $356 \mathrm{~ms}$ for incongruent, $353 \mathrm{~ms}$ for neutral, $331 \mathrm{~ms}$ for congruent, $\left.F_{(2,54)}=45.1, p<0.01\right)$ and training (RTs averaged across stimulus: $358 \mathrm{~ms}$ for pretraining, $336 \mathrm{~ms}$ for posttraining, $\left.F_{(1,27)}=2.8, p=0.03\right)$ in the physical Stroop. Likewise, in the aging group, accuracy did not change significantly as a function of training or stimulation group (all $p$ values $>0.7$ ). An analysis of RTs showed a main effect of stimulus (RTs averaged across pretraining and posttraining: $790 \mathrm{~ms}$ for incongruent, 733 $\mathrm{ms}$ for neutral, $684 \mathrm{~ms}$ for congruent, $F_{(2,54)}=81.9, p<0.001$ ) and training (RTs averaged across stimulus: $763 \mathrm{~ms}$ for pretraining, $709 \mathrm{~ms}$ for posttraining, $\left.F_{(1,27)}=5.3, p<0.03\right)$ in the number Stroop and a main effect of stimulus (RTs: $641 \mathrm{~ms}$ for incongruent, $592 \mathrm{~ms}$ for neutral, $575 \mathrm{~ms}$ for congruent, $F_{(2,54)}=$ $100.9, p<0.001)$ in the physical Stroop. Similar analyses were performed for the color and word Stroop tasks in the aging participants only; these revealed a main effect of stimulus (RTs averaged across pretraining and posttraining: $663 \mathrm{~ms}$ for incongruent, $586 \mathrm{~ms}$ for neutral, $587 \mathrm{~ms}$ for congruent, $F_{(2,54)}=$ $41.7, p<0.001)$ in the color Stroop and a main effect of stimulus (RTs averaged across pretraining and posttraining: $606 \mathrm{~ms}$ for incongruent, $594 \mathrm{~ms}$ for neutral, $577 \mathrm{~ms}$ for congruent, $F_{(2,54)}=$ $6.2, p=0.004$ ) and training (RTs averaged across stimulus: 608 $\mathrm{ms}$ for pretraining, $577 \mathrm{~ms}$ for posttraining, $F_{(1,27)}=4.4, p<$ $0.05)$ in the word Stroop. None of the other factors or their interaction reached significance (all $p$ values $>0.7$ ).

Because one of our hypotheses was of possible traininginduced changes in inhibitory abilities in aging participants, we performed a second set of analyses that focused specifically on participants' performance in the incongruent trials of each Stroop task, because these trials most strongly reflect possible changes in inhibitory abilities. Separate analyses based on accu- racy or RTs of pretraining and posttraining as within-subjects factor and stimulation group (parietal tRNS + training, training only, and motor tRNS + training) as between-subjects factor were run. These analyses revealed no training-induced change in accuracy in any of the Stroop tasks (all $p$ values $>0.5$ ). An equivalent analysis based on RTs showed a significant groupunspecific training-induced change in the number Stroop (RTs: $810 \mathrm{~ms}$ for pretraining, $771 \mathrm{~ms}$ for posttraining, $F_{(1,27)}=5.1, p=$ 0.03 ) and in the word Stroop tasks (RTs: $627 \mathrm{~ms}$ for pretraining, $590 \mathrm{~ms}$ for posttraining, $\left.F_{(1,27)}=4.0, p=0.05\right)$. None of the other factors or their interaction reached significance (all $p$ values $>0.8$; Fig. $3 B$ ). Lack of significant training-induced changes in the Stroop may be because this task is based on several abilities, for instance requiring perceptual interference and task maintenance demands besides inhibition (Buitenweg et al., 2012), which were not trained.

ANT paradigm: conflict component. Possible training-induced changes in inhibitory abilities were tested within each age group in terms of the conflict component of the ANT (Fan et al., 2002). Separate ANOVAs based on accuracy or RTs with stimulus type (congruent and incongruent) and training (pretraining vs posttraining) as within-subjects factors and stimulation group (parietal tRNS + training, training only, and motor tRNS + training) as between-subjects factor were run. In older participants, this analysis showed no significant change in accuracy after training and regardless of the stimulation group (all $p$ values $>0.8$ ). However, the same analysis based on RTs indicated a significant main effect of training $\left(F_{(1,27)}=18.1, p<0.001\right)$, trial type $\left(F_{(1,27)}=\right.$ 93.1, $p<0.001)$, and the interaction of training and stimulus $\left(F_{(1,27)}=6.0, p=0.02\right)$ and a marginal one between training, stimulus type, and stimulation group $\left(F_{(2,27)}=2.7, p=0.08\right)$. To better understand this three-way interaction, additional separate ANOVAs for each stimulus type and the same factors as above were run. These indicated that performance in congruent trials changed significantly after training $\left(F_{(1,27)}=7.3, p=0.01\right)$ but regardless of stimulation group (no significant interaction with stimulus, $\left.F_{(2,27)}=0.8, p=0.4\right)$. Likewise, performance in incongruent trials changed after training $\left(F_{(1,27)}=15.1, p=0.001\right)$, but, in contrast to congruent trials, the change marginally depended on the stimulation group (interaction with stimulus, $\left.F_{(2,27)}=2.8, p=0.07\right)$. Additional post hoc analyses of the incongruent trials only showed that the posttraining improvement (i.e., faster RTs) was larger in participants who received parietal stimulation and training (pretraining, $804 \mathrm{~ms}$; posttraining, 740 $\mathrm{ms})$ relative to those that received just training $\left(t_{(18)}=2.6, p<\right.$ 0.02 ) or training associated with motor stimulation $\left(t_{(18)}=2.1\right.$, $p=0.05$; Fig. $3 B$ ).

The equivalent analyses in younger participants showed no significant change in accuracy after training and regardless of the stimulation group (all $p$ values $>0.9$ ), whereas the analysis on RTs indicated a significant effect of training $\left(F_{(1,27)}=3.6, p=\right.$ $0.05)$; this is because RTs were faster after training regardless of stimulus (pretraining, $550 \mathrm{~ms}$; posttraining, $526 \mathrm{~ms}$ ), a change that might be attributable to practice with the task. There was also a main effect of stimulus $\left(F_{(1,27)}=76.1, p<0.001\right)$ because responses were faster for congruent than incongruent trials regardless of training (congruent, $505 \mathrm{~ms}$; incongruent, $582 \mathrm{~ms}$ ).

Navon paradigm: conflict component. Changes in inhibitory abilities in aging participants were also examined with the Navon paradigm (Navon, 1977; Romei et al., 2011). Separate analyses were performed on accuracy and RTs, with training (pretraining vs posttraining) and stimulus (congruent vs incongruent) as within-subjects factors and stimulation group (parietal tRNS + 
training, training only, and motor tRNS + training) as betweensubjects factor. Accuracy did not change significantly after training and regardless of the stimulation group (all $p$ values $>0.1$ ). A similar analysis on RTs showed a main effect of training $\left(F_{(1,27)}=\right.$ $6.8, p<0.02)$, reflecting a general training-induced change in speed across stimuli (RTs: pretraining, $574 \mathrm{~ms}$; posttraining, 553 $\mathrm{ms})$ and of stimuli $\left(F_{(1,27)}=80.8, p<0.001\right)$ because congruent trials were overall faster than incongruent ones (RTs, 544 vs 582 $\mathrm{ms})$. There was also a significant interaction between stimuli and stimulation group $\left(F_{(2,27)}=3.2, p=0.05\right)$ and a marginal one between training, stimulus, and stimulation group $\left(F_{(2,27)}=2.9\right.$, $p<0.07)$. No other effects reached significance.

To further understand the three-way interaction, additional separate analyses for each stimulus type (congruent and incongruent) were performed with the same factors as before. Performance in congruent trials improved after training (RTs: $554 \mathrm{~ms}$ for pretraining, $535 \mathrm{~ms}$ for posttraining, $F_{(1,27)}=5.8, p=0.02$ ) and regardless of the stimulation group (no significant interaction between stimulus and group, $\left.F_{(2,27)}=2.2, p=0.1\right)$. Likewise, there was a training-related improvement in performing incongruent trials (RTs: $593 \mathrm{~ms}$ for pretraining, $571 \mathrm{~ms}$ for posttraining, $\left.F_{(1,27)}=7.1, p<0.02\right)$ that depended on the stimulation group (significant interaction between stimulus and group, $\left.F_{(2,27)}=3.9, p=0.03\right)$, because participants who received parietal stimulation and training were faster than those who received either just training $\left(t_{(18)}=4.0, p=0.001\right)$ or training associated with motor stimulation $\left(t_{(18)}=2.8, p=0.01\right.$; Fig. $\left.3 B\right)$.

Additional analyses explored whether any of the significant training-induced changes in inhibitory abilities in aging participants of the parietal tRNS + training group were longstanding. Improvement in the incongruent trials of the ANT at 16 weeks after training did not significantly differ from either immediate posttraining $\left(t_{(9)}=0.9, p=0.4\right)$ or pretraining $\left(t_{(9)}=0.3, p=\right.$ $0.9)$ performance. Likewise, changes in the incongruent trials in the Navon task at 16 weeks after training showed no difference relative to both immediately after training $\left(t_{(9)}=-1.1, p>0.3\right)$ and before training $\left(t_{(9)}=-0.9, p>0.4\right)$. These results suggest that long-term performance in inhibitory abilities was better than at pretraining but not as proficient as at immediate posttraining; however, because these differences were not significant, the longterm effects of training and stimulation on untrained abilities still need additional clarifications.

\section{Attention and visual pattern recognition}

Here we tested whether the observed improvement in numerosity discrimination may reflect improvement in other nonquantity and non-inhibitory abilities, such as attention and recognition of visual patterns, which did not differ across stimulation groups and within each age group at pretraining (all $p$ values $>0.1$ )

A possible effect of training was examined for the alerting and orienting components of the attention network (Fan et al., 2002) in separate analyses for each age group. Specifically, for "alerting," an ANOVA based on RTs with stimulus type (cued and uncued) and training (pre vs post) as within-subjects factors and stimulation group (parietal tRNS + training, training only, and motor tRNS + training) as between-subjects factor was run. In older participants, this analysis showed a main effect of training $\left(F_{(1,27)}=6.1, p=0.02\right)$ because, regardless of the stimulus, RTs were faster after training (from 751 to $705 \mathrm{~ms}$ ); stimulus type was also significant $\left(F_{(1,27)}=100.2, p<0.001\right)$, because cued trials were responded to faster than uncued ones regardless of training (710 vs $745 \mathrm{~ms}$ ). No other effects or their interactions reached significance (all $p$ values $>0.9$ ). The same analysis performed on younger participants showed only a main effect of stimulus $\left(F_{(1,27)}=152.2, p<0.001\right)$, because cued trials were responded to faster than uncued ones regardless of training (501 vs $547 \mathrm{~ms}$ ). No other effects or their interactions reached significance (all $p$ values $>0.8$ ).

A similar analysis was performed for "orienting" based on RTs of centrally and spatially oriented trials and the other factors as above. In older participants, this analysis showed again a main effect of training $\left(F_{(1,27)}=6.4, p<0.02\right)$ because RTs were faster after training (from 734 to $688 \mathrm{~ms}$ ) regardless of the stimulus; stimulus type was also significant $\left(F_{(1,27)}=80.3, p<0.001\right)$, because spatially oriented trials were responded to faster than centrally oriented ones regardless of training (682 vs $740 \mathrm{~ms}$ ). No other effects or their interactions reached significance (all $p$ values $>0.8)$. The same analysis performed on younger participants showed a main effect of training $\left(F_{(1,27)}=6.1, p=0.02\right)$ because RTs were faster after training (from 560 to $549 \mathrm{~ms}$ ) regardless of the stimulus; stimulus type was also significant $\left(F_{(1,27)}=100.2, p\right.$ $<0.001)$, because spatially oriented trials were responded to faster than centrally oriented ones regardless of training (543 vs $560 \mathrm{~ms}$ ). No other effects or their interactions reached significance (all $p$ values $>0.5$; Fig. $3 C$ ).

Finally, we examined possible training-related effects in visual pattern recognition measured by the Navon task (Navon, 1977; Romei et al., 2011) in older participants and by face processing in younger ones (Pitcher et al., 2009). In the aging group, separate ANOVAs were performed with accuracy or RTs of global and local features and training (pre vs post) as within-subjects factors and stimulation group (parietal tRNS + training, training only, and motor tRNS + training) as between-subjects factor. Accuracy did not change after training (all $p$ values $>0.9$ ), whereas the analysis of RTs showed a significant main effect of stimulus $\left(F_{(1,27)}=47.5, p<0.001\right)$, because trials with global stimuli were performed faster than those with local stimuli regardless of training (520 vs $607 \mathrm{~ms}$ ). There was also a group-unspecific traininginduced change in speed $\left(F_{(1,27)}=6.8, p<0.02\right)$ that depended on the type of stimulus feature that was processed (significant interaction between training and stimulus, $F_{(1,27)}=3.9, p=$ $0.05)$. Specifically, after training and regardless of the stimulation group (no significant interactions with group, $p>0.5$ ), processing the local features of the stimuli became faster (from 626 to 588 $\left.\mathrm{ms}, t_{(29)}=3.1, p=0.005\right)$. No other effects reached significance.

In younger participants, visual pattern recognition did not change in accuracy or RT after training $\left(F_{(1,27)}=0.9, p=0.35\right.$ and $F_{(1,27)}=2.4, p=0.3$, respectively) and regardless of the stimulation group (no significant interaction of training and group in accuracy or RTs: $F_{(2,27)}=1.9, p=0.7$ and $F_{(2,27)}=2.1$, $p=0.25$, respectively; Fig. $3 C$ ).

\section{Arithmetic processing}

Because there are suggestions of a link between number acuity and proficiency in arithmetic tasks (Halberda et al., 2008; but see Butterworth, 2010), we explored whether the observed improvement in numerosity discrimination transferred to arithmetic abilities. At pretraining, participants' arithmetic abilities did not differ across stimulation groups within each age group (all $p$ values $>0.3$ ). Within each age group, separate repeated-measures ANOVAs with training (pre and post) as within-subjects factor and stimulation group (parietal tRNS + training, training only, and motor tRNS + training) as between-subjects factor were run on accuracy and RTs of correct responses obtained in the simple arithmetical tasks averaged across the three types of arithmetical problems. Both accuracy and RTs 
remained unchanged after training (young, $F_{(1,27)}=1.6, p=0.2$ and $F_{(1,27)}=2.8, p=0.1$; older, $F_{(1,27)}=0.9, p=0.3$ and $F_{(1,27)}=3.3$, $p=0.09$ ) and regardless of the stimulation group (no significant interaction of training and group: young, $F_{(2,27)}=0.9, p=0.44$ and $F_{(2,27)}=0.6, p=0.4$; older, $F_{(2,27)}=0.8, p=0.4$ and $F_{(2,27)}=0.1$, $p=0.8$; Fig. $3 C$ ). One possibility is that lack of training-related changes in arithmetical tasks may be because this arithmetic is not strongly related to numerosity discrimination (Butterworth, 2010; Szúcs et al., 2013); alternatively, no additional improvement was possible because performance in these tasks was already almost at ceiling in most participants.

These results suggest training-induced changes in performing some of the untrained cognitive tasks, specifically those measuring inhibitory abilities and visual pattern recognition in aging participants. Some of these changes were stimulation specific, i.e., performance improvement in older participants was higher in the parietal tRNS + training group relative to the other groups. These stimulation-specific changes in untrained tasks therefore suggest that at least part of the observed enhancement in numerosity discrimination may reflect improvements in other nonquantitybased cognitive abilities.

\section{Discussion}

This study investigated the cognitive processes underlying learning and whether they may change across the age spectrum. We coupled training with brain stimulation to test whether this may specifically boost the integration of information within a cognitive task or instead enhance the ability to inhibit task-irrelevant information. Our results show a substantial improvement $(\sim 19 \%)$ in both older and younger participants in performing a numerosity discrimination task after intensive and continuous repetition of the task. Across age groups, this improvement was significantly larger $(\sim 32 \%)$ and long lasting when training was coupled with parietal tRNS. The enhancement was much smaller when cognitive training was not associated with brain stimulation (sham) or when training was coupled with stimulation to a control region (bilateral motor areas). Moreover, in younger participants, improvement in numerosity discrimination corresponded to improvement in continuous quantity discrimination (time and space) and to decline in space discrimination in aging participants. In these aging participants, some inhibitory abilities also improved after training and more strongly in participants who received training associated with parietal stimulation. These results point to three main issues: (1) the age-comparable effects of training; (2) the age-dependent interaction with learning specific abilities (cue integration or inhibition); and (3) the age-dependent positive and negative transfer of learning to untrained abilities.

Enhanced performance in the training task did not differ across our age groups. This finding hints at the lifelong plasticity of the human brain (Park and Reuter-Lorenz, 2009; Bruno et al., 2012) despite reduced cognitive resources in the aging brain that may limit learning (Morrison and Chein, 2011; Shipstead et al., 2012). Some previous studies observed smaller performance enhancements in aging compared with younger subjects (Quartarone et al., 2008; Boggio et al., 2010; McAvinue et al., 2013), although suboptimal experimental designs were often used, i.e., inappropriate or unspecific measures to test changes in cognitive abilities, no control group, and very short or even a single training session (Noack et al., 2009; Shipstead et al., 2012). Our age-comparable improvements in numerosity discrimination may be explained by the use of intensive training based on a well specified and established paradigm, in association with other tasks that controlled for changes of more generalized abilities. Indeed, previous studies equally based on sufficiently long and appropriately controlled training showed similar training-induced changes in older and younger participants (Buschkuehl et al., 2008; Dahlin et al., 2008; Li et al., 2008; Zimerman et al., 2010, 2013). However, these studies neither elucidated the possible different mechanisms underlying learning nor manipulated them with brain stimulation.

Our age-comparable effects of training may also be explained by the use of brain stimulation, reflected in larger improvements when number training was combined with multi-session parietal tRNS. Brain stimulation, which is known for increasing cortical excitability (Terney et al., 2008; Fertonani et al., 2011), has often been used in young or clinical populations to improve behavior and learning (Hummel et al., 2005; Nitsche et al., 2008; Wu et al., 2008; Reis et al., 2009) but much more rarely in healthy aging people and, in these cases, in the form of a single-session direct current stimulation (Brown and Ridderinkhof, 2009; Reis et al., 2009; Boggio et al., 2010; Zimerman and Hummel, 2010). Instead, here we used multi-session RNS that alters cortex excitability by means of depolarizing the membrane resting potential and, crucially, also shortens the typically slow repolarization of the sodium channels with the repetitive application of random stimulation to these channels (Terney et al., 2008; Fertonani et al., 2011). Therefore, these processes may increase synaptic strength during learning associated with tRNS, which may explain the slower decay of long-term learning effects we observed in the trained task. tRNS is also known for enhancing the detection of weak neuronal signals, i.e., stochastic resonance (Wiesenfeld and Moss, 1995; Moss et al., 2004; Miniussi et al., 2010), which facilitates information processing in the brain (Wiesenfeld and Moss, 1995; Stein et al., 2005; Li et al., 2006). This is because random noise may make some neurons more sensitive to weak inputs that go in the same direction as the signal, such that enhanced performance can emerge as a result of the relation between noise and signal when the optimal level of noise is achieved (Fertonani et al., 2011). In the elderly brain, stochastic resonance may be particularly critical for improving performance because internal noise tends to increase with age (Welford, 1981; Bäckman et al., 2000), which in turn may account for impoverished cognitive performance (MacDonald et al., 2006). Therefore, improved signal detection via stochastic resonance may explain why applying random noise especially at high frequencies (Terney et al., 2008; Fertonani et al., 2011) enhanced performance in our aging participants, particularly when coupled with cognitive training (Reis et al., 2009).

We observed a significantly higher amelioration of performance after training and parietal stimulation. Enhancements in performance have been reported previously in the context of stimulation to visual and especially the motor areas (Terney et al., 2008; Fertonani et al., 2011), with the latter primarily made of giant pyramidal cells. The parietal areas we stimulated ( $\mathrm{P} 3$ and $\mathrm{P} 4$ ) broadly correspond to BA39/BA7 (Cortical Function, TransCranialTechnology, 2012; www.trans-cranial.com), which are characterized by a noticeable thinning of the cortex (Caspers et al., 2006) and a relatively heterogeneous cytoarchitecture, with granular cells intermingled with small pyramid cells (von Economo and Koskinas 1925; Caspers et al., 2006). These features are different from those characterizing the motor regions, whereby large pyramid cells with large fibers make it easy to induce changes in polarization (Fertonani et al., 2011). However, our results of parietal stimulation-induced changes in performance suggest that tRNS can promote changes in areas with different cytoarchitectures and that a critical issue for successful learning may be the association of stimulation with the appropriate training (Reis et al., 2009).

Having established a robust training-induced improvement in number acuity, we sought to examine whether this improvement reflected an enhancement of cue integration or inhibition. 
Our numerosity discrimination paradigm is particularly appropriate to distinguish between these abilities, which correspond to the combination of distinct quantity-based visual cues (number of items in a display and cumulative area covered) and to the inhibition of conflicting stimulus-size cues that are not relevant for the numerosity task (Hurewitz et al., 2006; Gebuis and Reynvoet, 2012; Szúcs et al., 2013; Cappelletti et al., 2014). Inhibiting task-irrelevant information is known for being vulnerable to aging (May and Hasher, 1998; Kane and Engle, 2003; Hasher et al., 2007), also in the case of numeracy (Cappelletti et al., 2014). However, poor performance in trials requiring inhibitory abilities may leave larger scope for improvement, which may explain why training and stimulation enhanced inhibitory abilities more strongly in aging than in younger participants. This agedependent distinction between the cognitive processes underlying training-induced changes in behavior highlights two main issues: (1) similar to other cognitive functions, numerosity discrimination also results from successful combination of different cognitive operations (Geibus et al., 2012; Gilmore et al., 2013; Szúcs et al., 2013); and (2) more broadly-the distinction between these operations can be critical to plan future training programs.

We observed age-specific transfer effects to untrained but related continuous quantity abilities: younger participants showed a parallel training-induced improvement in numerosity, time, and space. In contrast, aging participants' improved numerosity discrimination corresponded to a decline in space processing. We have interpreted previously young participants' positive transfer effects as reinforcing the suggestion of a link between time, space, and number (Walsh, 2003; Bueti and Walsh, 2009; Cantlon et al., 2009; Cappelletti et al., 2013). This link is also strengthened by the negative transfer we observed in space processing in the aging group. Negative transfer may be attributable to training-induced competition between excitatory and inhibitory synaptic changes supporting different adaptive and maladaptive cognitive processes (Mahncke et al., 2006; Ditye et al., 2013), a competition that may be more easily resolved in younger participants. Alternatively, negative transfer may also reflect lack of flexibility in the use of a strategy, which could be successful for a cognitive task but unsuccessful for another. For instance, in our aging participants, learning to suppress task-irrelevant information about continuous quantity in terms of stimulus size was successful in numerosity discrimination but detrimental in space discrimination in which continuous quantity processing is required to perform the task successfully.

Aging participants showed enhanced performance in other untrained tasks, especially those probing inhibitory abilities, in line with the improvement of those abilities in the trained numerosity task. Changes in inhibitory abilities were observed after parietal stimulation, although inhibition is typically more strongly associated with frontal brain areas (Garavan et al., 1999; Aron et al., 2004). However, the parietal lobe is part of a network involving frontal and some subcortical areas engaged in tasks probing inhibitory abilities (Garavan et al., 1999; Menon et al., 2001; Stevens et al., 2007), which may explain our observed changes in inhibitory abilities after training and stimulation.

In conclusion, our results emphasize age-related differences in the cognitive processes underlying learning and highlight the importance of identifying these processes when planning training programs.

\section{References}

Ambrus GG, Paulus W, Antal A (2010) Cutaneous perception thresholds of electrical stimulation methods: comparison of tDCS and tRNS. Clin Neurophysiol 121:1908-1914. CrossRef Medline
Anguera JA, Boccanfuso J, Rintoul JL, Al-Hashimi O, Faraji F, Janowich J, Kong E, Larraburro Y, Rolle C, Johnston E, Gazzaley A (2013) Video game training enhances cognitive control in older adults. Nature 501:97101. CrossRef Medline

Aron AR, Fletcher PC, Bullmore ET, Sahakian BJ, Robbins TW (2003) Stopsignal inhibition disrupted by damage to right inferior frontal gyrus in humans. Nature Neuroscience 6:115-116.

Bäckman L, Nyberg L, Lindenberger U, Li SC, Farde L (2006) The correlative triad among aging, dopamine, and cognition: Current status and future prospects. Neurosci Biobehav Rev 30:791-807. CrossRef Medline

Ball K, Berch DB, Helmers KF, Jobe JB, Leveck MD, Marsiske M, Morris JN, Rebok GW, Smith DM, Tennstedt SL, Unverzagt FW, Willis SL (2002) Effects of cognitive training interventions with older adults: a randomized controlled trial. JAMA 288:2271-2281. CrossRef Medline

Boggio PS, Campanhã C, Valasek CA, Fecteau S, Pascual-Leone A, Fregni F (2010) Modulation of decision-making in a gambling task in older adults with transcranial direct current stimulation. Eur J Neurosci 31:593-597. CrossRef Medline

Brown SB, Ridderinkhof KR (2009) Aging and the neuroeconomics of decision making: a review. Cogn Affect Behav Neurosci 9:365-379. CrossRef Medline

Bruno R, Merzenich M, Nudo R (2012) The fantastic plastic brain. Adv Mind Body Med 26:30-35. Medline

Bueti D, Walsh V (2009) The parietal cortex and the representation of time, space, number and other magnitudes. Philos Trans R Soc Lond B Biol Sci 364:1831-1840. CrossRef Medline

Buitenweg JIV, Murre JMJ, Ridderinkhof KR (2012) Brain training in progress: a review of trainability in healthy seniors. Front Hum Neurosci 6:183. CrossRef Medline

Buschkuehl M, Jaeggi SM, Hutchison S, Perrig-Chiello P, Däpp C, Müller M, Breil F, Hoppeler H, Perrig WJ (2008) Impact of working memory training on memory performance in old-old adults. Psychol Aging 23:743753. CrossRef Medline

Butterworth B (2010) Foundational numerical capacities and the origins of dyscalculia. Trends Cogn Sci 14:534-541. CrossRef Medline

Cantlon JF (2012) Math, monkeys, and the developing brain. Proc Natl Acad Sci U S A CrossRef

Cantlon JF, Brannon EM, Carter EJ, Pelphrey KA (2006) Functional imaging of numerical processing in adults and 4-y-old children. PLoS Biol 4:e125. CrossRef Medline

Cantlon JF, Platt ML, Brannon EM (2009) Beyond the number domain. Trends Cogn Sci 13:83-91. CrossRef Medline

Cappelletti M, Freeman ED, Cipolotti L (2009) Interactions and dissociations between time, numerosity and space processing. Neuropsychologia 47:2732-2748. CrossRef Medline

Cappelletti M, Freeman ED, Cipolotti L (2011) Number and time doubly dissociate. Neuropsychologia 49:3078-3092. CrossRef Medline

Cappelletti M, Gessaroli E, Hithersay R, Mitolo M, Didino D, Kanai R, Cohen Kadosh R, Walsh V (2013) Neuroenhancement: greatest, long-term and transferable quantity judgment induced by brain stimulation combined with cognitive training. J Neurosci 33:14899-14907. CrossRef Medline

Cappelletti M, Didino D, Stoianov I, Zorzi M (2014) Number skills are maintained in healthy aging. Cogn Psychol 69:25-45. CrossRef Medline

Caspers S, Geyer S, Schleicher A, Mohlberg H, Amunts K, Zilles K (2006) The human inferior parietal cortex: cytoarchitectonic parcellation and interindividual variability. Neuroimage 33:430-448. CrossRef Medline

Dahlin E, Neely AS, Larsson A, Bäckman L, Nyberg L (2008) Transfer of learning after updating training mediated by the striatum. Science 320: 1510-1512. CrossRef Medline

Ditye T, Kanai R, Bahrami B, Muggleton NG, Rees G, Walsh V (2013) Rapid changes in brain structure predict improvements induced by perceptual learning. Neuroimage 81:205-212. CrossRef Medline

Fan J, McCandliss BD, Sommer T, Raz A, Posner MI (2002) Testing the efficiency and independence of attentional networks. J Cogn Neurosci 14:340-347. CrossRef Medline

Fertonani A, Pirulli C, Miniussi C (2011) Random noise stimulation improves neuroplasticity in perceptual learning. J Neurosci 31:1541615423. CrossRef Medline

Garavan H, Ross TJ, Stein EA (1999) Right hemispheric dominance of inhibitory control: an event-related functional MRI study. Proc Natl Acad Sci U S A 96:8301-8306. CrossRef Medline

Gebuis T, Kenemans JL, de Haan EH, van der Smagt MJ (2010) Conflict 
processing of symbolic and non-symbolic numerosity. Neuropsychologia 48:394-401. CrossRef Medline

Gebuis T, Reynvoet B (2012) Continuous visual properties explain neural responses to non-symbolic number. Psychophysiology 49:1481-1491. CrossRef Medline

Gilmore C, Attridge N, Clayton S, Cragg L, Johnson S, Marlow N, Simms V, Inglis M (2013) Individual differences in inhibitory control, not nonverbal number acuity, correlate with mathematics achievement. PLoS One 8:e67374. CrossRef Medline

Gottwald RL, Garner WR (1972) Effects of focusing strategy on speeded classification with grouping, filtering and condensation tasks. Percept Psychophys 11:179-182. CrossRef

Halberda J, Mazzocco MM, Feigenson L (2008) Individual differences in nonverbal number acuity predict maths achievement. Nature 455:665668. CrossRef Medline

Halberda J, Ly R, Wilmer J, Naiman DQ, Germine L (2012) Number sense across the lifespan as revealed by a massive Internet-based sample. Proc Natl Acad Sci U S A 109:11116-11120. CrossRef Medline

Hasher L, Lustig C, Zacks RT (2007) Inhibitory mechanisms and the control of attention. In: Variation in working memory (Conway A, Jarrold C, Kane M, Miyake A, Towse AJ, eds), pp 227-249. New York: Oxford UP.

Henik A, Tzelgov J (1982) Is three greater than five: the relation between physical and semantic size in comparison tasks. Mem Cognit 10:389-395. CrossRef Medline

Hummel F, Celnik P, Giraux P, Floel A, Wu WH, Gerloff C, Cohen LG (2005) Effects of non-invasive cortical stimulation on skilled motor function in chronic stroke. Brain 128:490-499. CrossRef Medline

Hurewitz F, Gelman R, Schnitzer B (2006) Sometimes area counts more than number. Proc Natl Acad Sci U S A 103:19599-19604. CrossRef Medline

Kane MJ, Engle RW (2003) Working-memory capacity and the control of attention: the contributions of goal neglect, response competition, and task set to Stroop interference. J Exp Psychol Gen 132:47-70. CrossRef Medline

Lee H, Boot WR, Basak C, Voss MW, Prakash RS, Neider M, Erickson KI, Simons DJ, Fabiani M, Gratton G, Low KA, Kramer AF (2012) Performance gains from directed training do not transfer to untrained tasks. Acta Psychol (Amst) 139:146-158. CrossRef Medline

Li SC, Farde L, Nyberg L, Lindenberger U, Backman L (2006) A neurocomputational model of stochastic resonance and aging. Neurocomputing 69:1553-1560. CrossRef Medline

Li SC, Schmiedek F, Huxhold O, Röcke C, Smith J, Lindenberger U (2008) Working memory plasticity in old age: practice gain, transfer and maintenance. Psychol Aging 23:731-742. CrossRef Medline

MacDonald SW, Nyberg L, Bäckman L (2006) Intra-individual variability in behavior: links to brain structure, neurotransmission, and neuronal activity. Trends Neurosci 29:474-480. CrossRef Medline

Mahncke HW, Bronstone A, Merzenich MM (2006) Brain plasticity and functional losses in the aged: scientific bases for a novel intervention. Prog Brain Res 157:81-109. CrossRef Medline

May CP, Hasher L (1998) Synchrony effects in inhibitory control over thought and action. J Exp Psychol Human Percept Perform 24:363-379. CrossRef Medline

McAvinue LP, Golemme M, Castorina M, Tatti E, Pigni FM, Salomone S, Brennan S, Robertson IH (2013) An evaluation of a working memory training scheme in older adults. Front Aging Neurosci 5:20. CrossRef Medline

Menon V, Adleman NE, White CD, Glover GH, Reiss AL (2001) Error-related brain activation during a Go/NoGo response inhibition task. Hum Brain Mapp 12:131-143. CrossRef Medline

Mevorach C, Humphreys GW, Shalev L (2006) Opposite biases in saliencebased selection for the left and right posterior parietal cortex. Nat Neurosci 9:740-742. CrossRef Medline

Miniussi C, Ruzzoli M, Walsh V (2010) The mechanism of transcranial magnetic stimulation in cognition. Cortex 46:128-130. CrossRef Medline

Morrison AB, Chein JM (2011) Does working memory training work? The promise and challenges of enhancing cognition by training working memory. Psychon Bull Review 18:46-60. CrossRef Medline

Moss F, Ward LM, Sannita WG (2004) Stochastic resonance and sensory information processing: a tutorial and review of application. Clin Neurophysiol 115:267-281. CrossRef Medline

Mulquiney PG, Hoy KE, Daskalakis ZJ, Fitzgerald PB (2011) Improving working memory: exploring the effect of transcranial random noise stim- ulation and transcranial direct current stimulation on the dorsolateral prefrontal cortex. Clin Neurophysiol 122:2384-2389. CrossRef Medline

Navon D (1977) Forest before trees: the precedence of global features in visual perception. Cogn Psychol 9:353-383. CrossRef

Nitsche MA, Cohen LG, Wassermann EM, Priori A, Lang N, Antal A, Paulus W, Hummel F, Boggio PS, Fregni F, Pascual-Leone A (2008) Transcranial direct current stimulation: state of the art 2008. Brain Stimul 1:206223. CrossRef Medline

Noack H, Lövdén M, Schmiedek F, Lindenberger U (2009) Cognitive plasticity in adulthood and old age: gauging the generality of cognitive intervention effects. Restor Neurol Neurosci 27:435-453. CrossRef Medline

Park DC, Reuter-Lorenz P (2009) The adaptive brain: aging and neurocognitive scaffolding. Annu Rev Psychol 60:173-196. CrossRef Medline

Piazza M, Izard V, Pinel P, Le Bihan D, Dehaene S (2004) Tuning curves for approximate numerosity in the human intraparietal sulcus. Neuron 44 547-555. CrossRef Medline

Pitcher D, Charles L, Devlin JT, Walsh V, Duchaine B (2009) Triple dissociation of faces, bodies, and objects in extrastriate cortex. Curr Biol 19: 319-324. CrossRef Medline

Pomerantz JR, Pristach EA (1989) Emergent features, attention, and perceptual glue in visual form perception. J Exp Psychol Hum Percept Perform 15:635-649. CrossRef Medline

Reis J, Schambra HM, Cohen LG, Buch ER, Fritsch B, Zarahn E, Celnik PA, Krakauer JW (2009) Noninvasive cortical stimulation enhances motor skill acquisition over multiple days through an effect on consolidation. Proc Natl Acad Sci U S A 106:1590-1595. CrossRef Medline

Romei V, Driver J, Schyns PG, Thut G (2011) Rhythmic TMS over parietal cortex links distinct brain frequencies to global versus local visual processing. Curr Biol 21:334-337. CrossRef Medline

Roudaia E, Farber LE, Bennett PJ, Sekuler AB (2011) The effects of aging on contour discrimination in clutter. Vis Res 51:1022-1032. CrossRef Medline

Shepp BE, Barrett SE (1991) The development of perceived structure and attention: evidence from divided and selective attention tasks. J Exp Child Psychol 51:434-458. CrossRef Medline

Shipstead Z, Redick TS, Engle RW (2012) Is working memory training effective? Psychol Bull 138:628-654. CrossRef Medline

Siegel AW (1968) Variables affecting incidental learning in children. Child Dev 39:957-968. CrossRef Medline

Stein RB, Gossen ER, Jones KE (2005) Neuronal variability: noise or part of the signal? Nat Rev Neurosci 6:389-397. CrossRef Medline

Stevens MC, Kiehl KA, Pearlson GD, Calhoun VD (2007) Functional neural networks underlying response inhibition in adolescents and adults. Behav Brain Res 181:12-22. CrossRef Medline

Stroop JR (1935) Studies of interference in serial verbal reactions. J Exp Psychol 18:643-662. CrossRef

Szúcs D, Nobes A, Devine A, Gabriel FC, Gebuis T (2013) Visual stimulus parameters seriously compromise the measurement of approximate number system acuity and comparative effects between adults and children. Front Psychol 4:444. CrossRef Medline

Terney D, Chaieb L, Moliadze V, Antal A, Paulus W (2008) Increasing human brain excitability by transcranial high-frequency random noise stimulation. J Neurosci 28:14147-14155. CrossRef Medline

von Economo C, Koskinas GN （1925） Die Cytoarchitektonik der Hirnrinde des Erwachsenen Menschen: Textband und Atlas mit 112 Mikrophotographischen Tafeln. Vienna: Springer.

Walsh V (2003) A theory of magnitude: Common cortical metric of time, space and quantity. Trends Cogn Sci 7:483-488. CrossRef Medline

Welford AT (1981) Signal, noise, performance, and age. Hum Factors 23: 97-109. Medline

Wiesenfeld K, Moss F (1995) Stochastic resonance and the benefits of noise: from ice ages to crayfish and SQUIDs. Nature 373:33-36. CrossRef Medline

Wu AD, Fregni F, Simon DK, Deblieck C, Pascual-Leone A (2008) Noninvasive brain stimulation for Parkinson's disease and dystonia. Neurotherapeutics 5:345-361. CrossRef Medline

Zimerman M, Hummel FC (2010) Non-invasive brain stimulation: enhancing motor and cognitive functions in healthy old subjects. Front Aging Neurosci 2:149. CrossRef Medline

Zimerman M, Nitsch M, Giraux P, GerloffC, Cohen LG, Hummel FC (2013) Neuroenhancement of the aging brain: restoring skill acquisition in old subjects. Ann Neurol 73:10-15. CrossRef Medline 